\title{
THE ROLE OF TECHNICAL MEASUREMENTS IN QUALITY OF SERVICES IN TOURISM: SMART SENSOR HUB FOR WELLBEING
}

Tamara Jakovljević

University of Belgrade, Faculty of Organizational Sciences, Belgrade, Serbia
Correspondence:

Tamara Jakovljević

e-mail:

tamara.jakovljevic@lotric.rs

\section{Abstract:}

This paper deals with the influence and applicability of technical measurements in creation a new offer for innovative tourism and its reflection on tourism quality. It discusses the potential of measuring the environmental and human body conditions in order to achieve the best solutions for wellbeing. That can also be used as a new measure of customers and requirements satisfaction, as one of the most important facts for tourism offer and quality management. The paper is addressed to decision makers, quality and tourism managers, who consider innovation a competitive advantage.

\section{Keywords:}

measurement, quality management system, tourism, innovative tourism, tourism quality.

\section{INTRODUCTION}

The authors shall start by saying something about the field of interest of this paper, i.e. the quality and tourism. If we look closer at the development of quality and quality movement in general, we can conclude that the fundamental needs for the emergence of quality on the global market and society can be generated from the quality movement development. Namely, it dates back to the medieval period in Europe, where the craftsmen were organized in unions, so-called guilds, in the late $13^{\text {th }}$ century. Quality management in the guilds assumed a very important place. It created check-ups, controls and certain forms of audit, performed by craftsmen, to ensure compliance with the quality specifications (Filipović \& Đurić, 2008).

The quality system is defined as "a set of interrelated or interacting elements using a variety of resources to achieve the quality-related objectives." These are focused on fulfilling and overcoming the user's requirements (Filipović \& Đurić, 2010).

Furthermore, ensuring quality facilities or services for tourists is an essential factor for generating sustainable products, particularly in terms of smaller and less accessible market segments that are heavily dependent on the natural and cultural heritage. If high-quality tourism products are generated, it is more likely that the tourists will be more satisfied and will have positive travel experiences. Additionally, they will most probably stay longer, return to the destination, recommend it to others and would care about the preservation of the local heritage (European Commission, 2002). 
Tourism is one of the key development sectors in all countries and the main source of income, jobs and wealth creation. It also plays an important role in promoting the country's image externally and shaping the complementary domestic policies. Policy makers and tourism experts should devote considerable attention to understanding the country's tourism competitiveness and providing evidence necessary for the decision making process (Dupeyras \& MacCallum, 2013).

As regards the quality of services, considerable attention is devoted to providing a personalized, genuine and informed service with the aim to be as efficient and professional as possible (European Commission, 2002).

Therefore, measurement can be beneficial in numerous ways in terms of tourism and quality of services. Usually, what is taken into account is a subjective attitude of users, but technical measurements may enable us to improve our offer using an innovative approach to tourism.

\section{TECHNICAL MESAUREMENTS}

Thus, it is necessary to perform measurements as human beings first began trading with their neighbors. Besides trading, early societies also had to perform various other tasks. The change from leading a nomadic life to settling in one place imposed the necessity of performing other measurements, such as those of land and building materials (UNIDO, 2006).

Technical measurements represent a group of measurement actions whose aim is to make the supplier and/ or acquirer conversant with the process of development of technical solutions, ongoing assessment of the related risks and issues, and the probability of fulfilling the vital objectives of the acquirer. It is planned at an early stage of the life cycle and performed with considerable and ever-growing level of commitment along with the development of technical solution (US Army, 2005).

In case of prosperous measurement implementation, the results are used by the management for decision making. It can also be used for operations needed to reduce risks or potential problems.

In daily activities, decision makers cannot wait for perfect data to plan their businesses, but they can rely on the analysis of the best available data complemented with real-time events and qualitative insight.

Risk management aims at determining information needs that can have a bearing on the project and organizational performances and which should be objectively explained with the measurement results. The measure- ment data helps to quantify risks, and provides information about whether risks have been successfully mitigated (US Army, 2005).

\section{MEASUREMENT IN TOURISM}

There is a different set of criteria for tourism measurements, particularly in terms of quality. If we talk first about competitiveness, we could find a few significant initiatives at industry level.

Evidence reveals that the country's initiatives towards producing competitiveness indicators remain rather partial and unequal in terms of content.

In OCED tourism papers we find a definition based on the understanding of the key elements related to tourism competitiveness. It shows that the competitiveness of a destination is determined by its ability to optimize its assets for the residents and visitors, to provide consumers with quality, innovation and uniqueness of its tourist offer, but also, to prove that the available resources stimulate tourism and are being used efficiently and sustainably.

Also, we can see that the key indicators for competence analysis have been determined. They are divided into four categories and are, as follows (Dupeyras \& MacCallum, 2013):

- Indicators measuring the tourism performance and impacts;

- Indicators monitoring the ability of a destination to deliver quality and competitive tourism services;

- Indicators monitoring the destination attractiveness;

- Indicators describing policy responses and economic opportunities.

In the remaining part of the paper, we may use the given indicators for solving the case studies and determining the correlation between technical measurements and finding innovative solutions in tourism.

\section{Measurability of quality in hospitality categorization}

In numerous countries, the basic required hotel services are determined by law. That means that by providing that minimum, we actually provide the basic guarantee of quality. That minimum is the foundation for achieving the mandatory quality and categorization.

According to Kosar (2012), categorization represents the process of rating mandatory quality based on the predefined criteria and it encompasses environ- 
mental, technological, organizational and procedural features of the hotel product.

In another case, technical and technological categorizations need to be measured against the precise indicators. This applies to the quality components that are easy to measure. On the other hand, categorization of provided services, as well as consideration of certain processes, is more difficult to evaluate relying on the quality and turn into measurable categories. It is certainly important to find methods and techniques to measure services, in order to deliver the report on the quality of services provided.

\section{Measuring the employee competence}

Competence is a set of knowledge, skills and attitudes that are vital for the overall business performances, and it can be measured on the basis of the predefined standards and enhanced through continuous education and training (Lucia \& Lepsinger, 1999). Competitiveness can be explained by three groups of characteristics: knowledge required for work, desire for work and opportunity for work (Stanivuković, 2000).

\section{Measuring quality in the context of compatibility} with the tourists requirements

According to Kosar (2012), this means comparing the level of satisfying the consumers' needs and the level of their satisfaction. That means that the emphasis should not solely be on the services provided, but also on how they are provided. The difference between the two could be measured using the statistical methods, which should be used to track and interpret the consumers' behavior. The results should point to the mistakes in the service and help to eliminate them for the sake of improving the overall quality.

\section{Measuring Visitor Satisfaction}

One of the key measurement categories in tourism is visitor satisfaction, which is influenced by recommendations, as well as quality indicators. Feedback provided by visitors is very important for evaluating the quality. When it comes to the visitors themselves, their decisions are partly influenced by the media which provide information on the given location.

That is perhaps the main indicator for identifying and comprehending the consumers' behavior, and the value of their experience when creating new offers.

\section{QUALITY OF LIFE AND TOURISM}

Life quality is defined as an individual's perception of their position in the context of culture and related value systems and in agreement with their goals, expectations, standards and concerns.

It is a broad-ranging concept incorporating in a complex way the person's physical health, psychological state, level of independence, social relationships, personal beliefs and their relationship with the salient features of the environment (The WHOQOL Group, 1995).

The quality of life (QOL) concept can considerably vary along the dimension of objective and subjective, normative and individualized. Subjective QOL is a broad term that covers happiness, subjective wellbeing, and life satisfaction (Sirgy, 2001). The studies on subjective QOL place special emphasis on personal experience and perceptions about one's life quality. The term can sometimes be used reciprocally with "subjective well-being" of individuals in the literature (Costanzaa et al., 2007).

Subjective well-being can also be defined as customers' perception and satisfaction with his/her overall life quality.

\begin{tabular}{lc}
\hline \\
\hline OBJECTIVE \\
INDICATORS
\end{tabular}

Figure1. Objective and subjective measures of QOL Source: Michalos (2008)

\section{Quality-of-Life Measures}

There are two main approaches to measuring life quality: objective and subjective. These entail diverse conceptualization and understanding of the notion. The difference between subjective and objective measures of QOL is determined based on their connection with customers' "subjective awareness" (Veenhoven 2006). 
Objective indicators are not much subject to awareness of tourists and guests. For instance, income level of an individual does not change along with his or her perception. On the other hand, subjective QOL indicators are immediately affected by perceptual differences and subjective assessments (Costanzaa et al., 2007; Galloway, 2006).

\section{Tourist Satisfaction and QOL}

The research on the quality of life is undoubtedly connected to the consumer satisfaction, or visitors, in the case of tourism. Frich (2006) interchangeably uses the concepts of life satisfaction and quality-of-life. $\mathrm{He}$ believes that providing personal reports on service satisfaction significantly correlates with the satisfaction with the quality of life.

Personal satisfaction is also affected by a person's career and family, which has an effect on their overall wellbeing.

\section{Wellbeing}

The quality of life is also identified as an overall wellbeing comprising objective descriptors and subjective evaluations of physical, material, social and emotional well-being along with the level of personal development and purposeful activity weighted by a personal set of values (Felce \& Perry, 1993).
Well-being has been defined by personal characteristics of an innately positive condition (happiness). It has also been defined based on how self-esteem can be measured on a continuum from positive to negative. It can also be formulated in terms of one's context (standard of living), absence of well-being (depression), or in a collective manner (Pollard \& Lee, 2003).

As written in the report "Wellbeing and policy", countries worldwide are becoming attracted to these appealing ideas but are worried about how they can be implemented in real life. The authors are of the opinion that such ideas could encourage the governments and individuals to make 'better' decisions that would contribute to enhancing the overall wellbeing.

Chancellor Merkel pointed to the relevance of the notion of wellbeing by stressing the following: Industrialized countries do not only have the GDP and growth issues.

Even hard-nosed central bankers, like Ben Bernanke, have argued: The ultimate purpose of economics, of course, is to understand and promote the enhancement of wellbeing.

Very few academics would argue that a country should invest efforts into maximizing the GDP.

The connection between tourism and economic development has long been recognized by both theoreticians and experts looking for development solutions for third-world countries and the overall reduction of poverty.

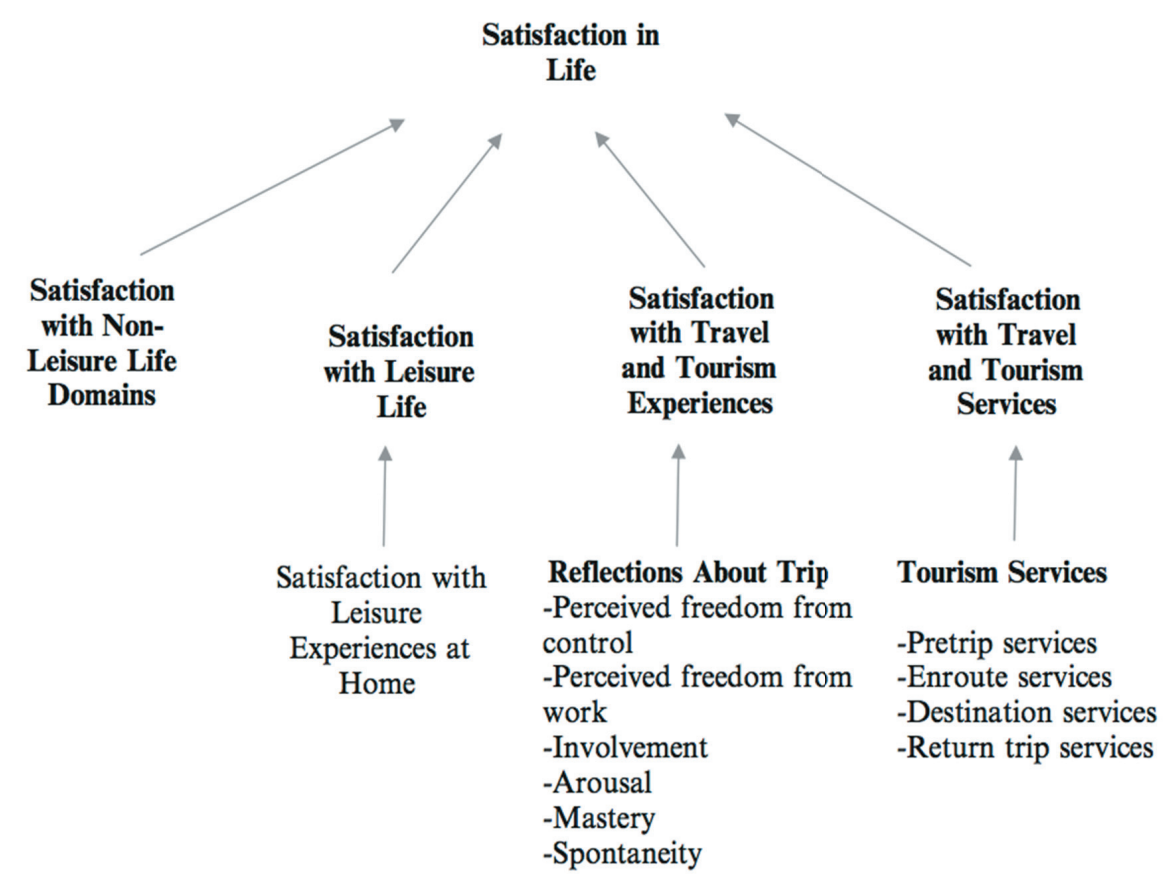

Figure 2. Subjective Aspects of Tourists' Quality-of-Life (QOL)

Source: Adapted from Neal et al. 2007. 


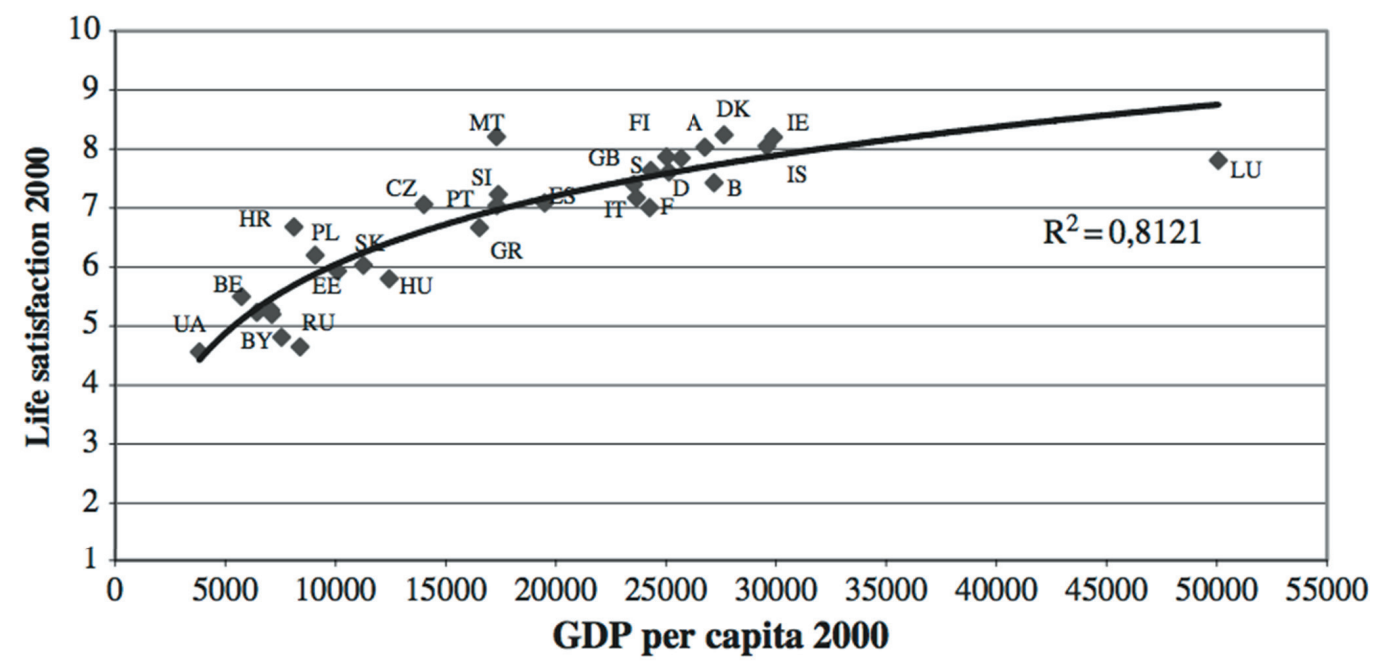

Figure 3. Life satisfaction - selected EU-countries 1973-2003 (\% very/fairly satisfied) Database: Eurobarometer. Source: Møller (2008)

Tourism encompasses both wellbeing and the quality of life. Since tourism provides rest, relaxation and new experiences, that in itself increases the degree of the quality of life and wellbeing in general.

Also, this should be used as a basis when creating new forms of tourist offers, which should aim to have a positive effect on sustainable development and social responsibility, which in turn are closely tied to the concept and the increase of subjective wellbeing and the quality of life.

\section{LOTRIČ METROLOGY: A CASE STUDY}

Lotrič Metrology originated from a laboratory that was founded in 1923 and was established as a company in 1992.

This Slovenian based group deals with all kinds of measurements, includeing calibrations, testing, conformity assessment, metrology solutions, and representations.

Lotrič Metrology Group develops their business following the motto "When you think about measurement, you think about LOTRIČ Metrology" because, as William Shakespeare had said, "There is a measure in everything".

The central points of group development are the quality system, standardization and certification, as well as the strategy and co-operation with stakeholders.

Under the Slovenian Accreditation, they have done 58.162 metrology checks; they cover more than $95 \%$ of needs in the field of measurement and have 4 patents.
Consequently, they use measurements in their own business. they have accreditation and measure for others, with the motto "We measure, you grow". The results show that they have been recognized as a symbol of quality, excellence and trust by the market.

In a new phase of business development, Lotrič created its first market product, a smart sensor hub "Exactum", which had its world premiere at Milan Expo 2015.

We can now see in practice a new concept for measuring wellbeing parameters with the support of sensor technologies, which can also help us create some innovative solutions in tourism.

Sensors monitoring environmental parameters in wellbeing: quality of air, temperature, relative humidity, air velocity and airflow, noise level, light level, pool water quality, as well as pressure difference.

By monitoring those parameters, we can ensure the comfort for tourists, residents, employees and visitors. That is also helpful in reducing the risk of human error, avoiding damage to cases and for getting reports of continual or discontinued measured conditions in hotels, apartments, rooms, wellness and sport centers etc.

Once we know the optimal values for wellbeing, we can manage the desired conditions in order to provide the best enjoyment for our guests.

We will now address the issue of technical measurements in tourism, and how such parameters can help us save time, improve quality and be innovative.

What are the benefits of Exactum?

- Continuous measuring and access to results Exactum wellbeing automatically collects the measured values from measuring points equipped 
with sensors. A smart sensor hub manages the system. Remote access control allows us to access the collected results in one place and monitor measurements in real time.

- Immediate warning and response

In the event that the environmental parameters exceed the prescribed limit values, Exactum wellbeing sends a warning by electronic mail or text message. This will allow us to respond in a timely manner and take immediate action.

- Well-ordered database, reporting and archiving Exactum wellbeing enables automatic saving, generation of reports, drawing graphs, reviewing of past measurements and critical events. Manual recording is no longer required. All of the selected data can be exported to .pdf or .xlsx formats and used for analysis.

When we have the data we can analyze, compare and manage it for further strategies and development of tourism offer. This actually means that we can control, prevent and improve parameters which affect the quality in tourism. We can also reduce our costs using the Cost of Quality methodology.

That involves the use of methodology which enables organizations to determine which resources are being used for activities that prevent low levels of quality. This applies to organizations that provide services and prod- ucts as well as the activities they undertake in order to prevent bad quality, created by internal or external errors. In this case, if we are given information and data on time, we can provide a timely reaction and prevent damage.

This system allows us to improve the processes by measuring environmental conditions, tourist satisfaction and QOL (wellbeing). This could contribute to satisfying consumers' demands and contribute to their satisfaction through prevention and constant advancement based on the subjective and objective evaluation and measurement.

\section{CONCLUSION}

Numerous factors have a considerable bearing on tourists' perception of a destination, regarding the level of their satisfaction, as well as tourists' willingness to repeat their visit and recommend the destination to prospective visitors (European Commission, 2002).

Measurements can help us to create new innovative views and solutions. Implementing Exactum (smart sensor hub) to our process is also becoming compatible with PDCA circle, also known as Deming circle (PlanDo-Check-Act). The program allows us to plan, conduct and monitor our desired valued and conditions, and act when necessary.

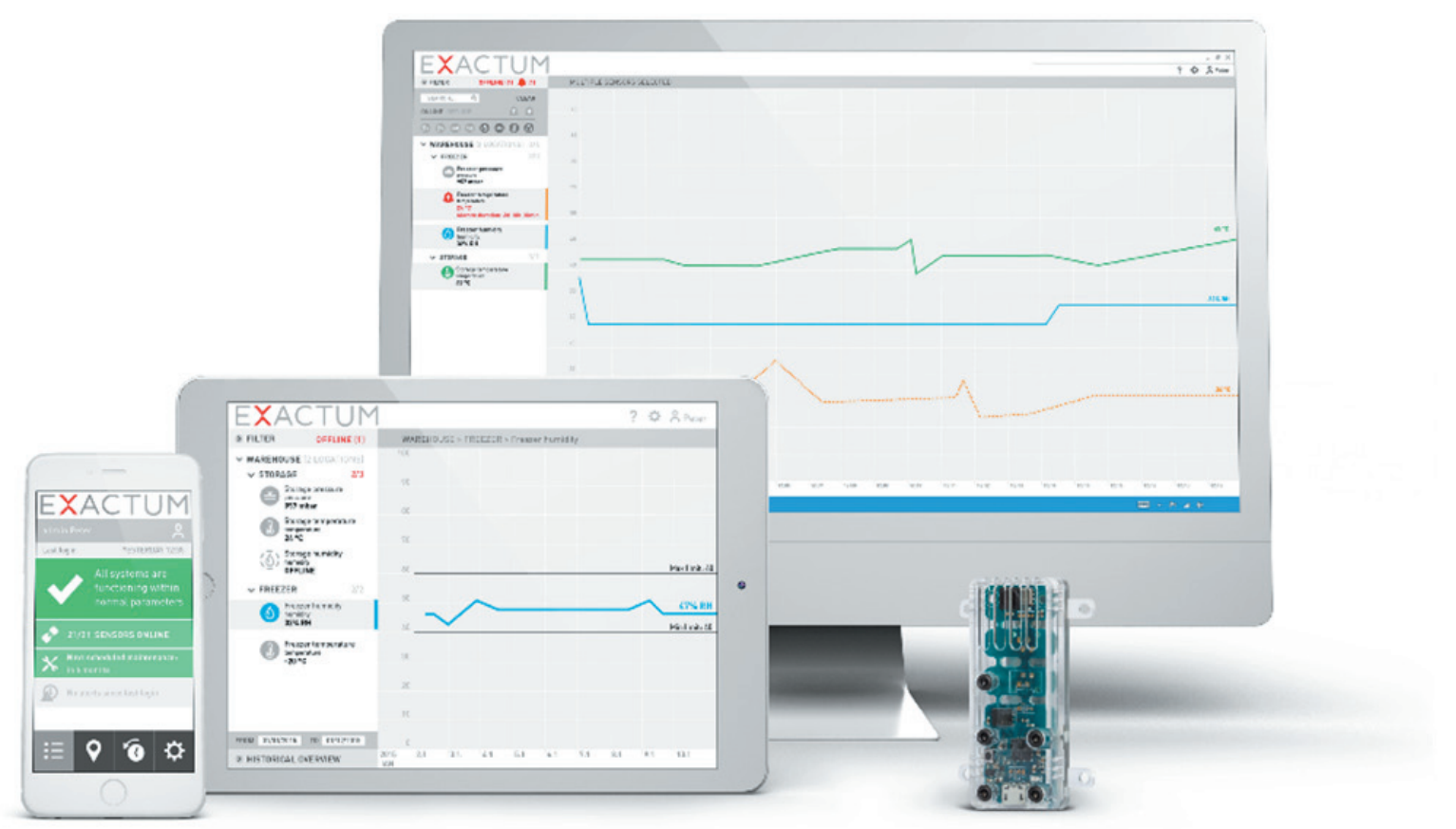

Figure 4. Monitoring parameters in Exactum software

Source: www.exactum.si 
It also analyses the notion of Total Quality Management (TQM), as a means of fulfilling the organization's goals by enhancing the customer's experience of the product or services provided. It is concerned with the efficient use of resources, and the level of participation and satisfaction of human resources in an organization (European Commission, 2000). It admits that an organization can have a wider scope of objectives and should achieve them in an integrated way.

According to the same report, Integrated Quality Control, as the leading European initiative, aims to contribute to the advancement and implementation of directions which lead to tourism quality. The quality of tourism service is high provided that the visitor positively rates his/her satisfaction with that service and demand. That is why it is important to discover all the aspects of customer's experience, so that the quality could be provided and related costs minimised. Measuring environmental parameters allows us to ensure that the tourist is provided with the desired conditions through value reports or allowing them to set the desired conditions on their own.

That could become a new comparative advantage for providers of tourism services. It can also help the decision makers with risk management, as mentioned at the beginning of the paper, and the role of technical measurement.

In further research, we could measure not only the environmental parameters and tourist satisfaction and the effect of smart sensor hub implementation on satisfaction of user requirements and quality, but also use this sensor for technical measurement of the human body in order to compare the parameters of wellbeing and subjective wellbeing of visitors.

Innovation is at the heart of any successful company's agenda, so the role that innovation plays in securing competitiveness is a very important topic.

The importance of innovation in service activities was underestimated for a long time, as innovations in services and tourism were secondary and underfunded. Thus, they were excluded from the scope of government interest and action. It is worth noting that the discourse altered with the emergence of new information and communication technologies, which have been particularly significant in tourism. The dissemination of new production modes and the resulting organizational shockwaves, along with the marketing adjustments entailed, have been a widely explored research topic (Dupeyras \& MacCallum, 2013).

Another advantage of Exactum smart sensor hub is that we have access to the data it measures in real time and we could also access it using a mobile application. It is possible to limit the access to the authorized people, while creating a special application for customers, which wouldn't be able to set parameters until they arrived at their destination or could only be used during their visit. Therefore, we have a complete innovative circle which follows the current trends in information and technical revolution. In order to get the results, it is important to keep continuously learning, checking and improving all the processes. This represents the only way for the organisation to achieve its goals and improve the quality of services.

\section{REFERENCES}

Filipović, J., \& Đurić, M. (2009). Fundamentals of Quality. Belgrade: Faculty of Organizational sciences.

Filipovic, J., \& Đurić, M. (2010). Quality management system. Belgrade: Faculty of Organizational sciences.

European Commission. (2002). Using natural and cultural heritage to develop sustainable tourism in non-traditional tourist destinations. Luxembourg: European Commission.

Dupeyras, A., \& MacCallum, N. (2013). Indicators for Measuring Competitiveness in Tourism: A Guidance Document. Paris: OCED Publishing. doi:10.1787/5k47t9q2t923-en

UNIDO. (2006) Role of measurement and calibration in the manufacture of products for the global market. Retrieved September 1, 2016 from https://www.unido. org/fileadmin/user_media/Publications/Pub_free/ Role_of_measurement_and_calibration.pdf

Garry, J. R., Lockheed, M., \& Cheryl, J. (2005). Technical Measurement. Retrieved September 1, 2016 from http://www.incose.org/docs/default-source/ProductsPublications/technical-measurement-guide--dec-2005.pdf?sfvrsn=4

Kosar, Lj., \& Kosar, N. (2012). Basic aspects of quality in tourism and hospitality. Quaestus Multidiscliplinary Research Journal, 3, 27-37.

Anntoinette, L.D., \& Lepsinger, R. (1999). The Art and Science of Competency Models. San Francisco: JosseyBass Pfeiffer.

Stanivuković, D. (2000). Human resources - moving spirit of change. Belgrade: JUSK Jugoslavian Association for Standardization and Quality.

The WHOQOL Group. (1998). The World Health Organization Quality of Life Assessment (WHOQOL): development and general psychometric properties. Social Science and Medicine, 46(12), 1569-1585. doi:10.1016/S0277-9536(98)00009-4

Sirgy, M.J. (2001). Handbook of quality of life research: An ethnical marketing perspective. Dordrecht: Kluwer Academic. 
Costanzaa, R. et al. (2007). Quality of life: An approach integrating oppor- tunities, human needs and subjective well-being. Ecological Economics, 61(2-3), 267-276. doi:10.1016/j.ecolecon.2006.02.023

Gursoy, D., \& Rutherford, D. (2004). Host attitudes toward tourism: An Improved Structural Model. Annals of Tourism Research, 31(3), 495-516. doi:10.1016/j.annals.2003.08.008

Veenhoven, R. (2006). How do we assess how happy we are? Tenets, implications and tenability of three theories. Notre Dame: University of Notre Dame.

Galloway, S. (2006). Quality of life and well-being: Measuring the benefits of culture and sport. Edinburgh: Scottish Executive Social Research.

Cummins, R.A. (1996). The domains of life satisfaction: An attempt to order chaos. Social Indicators Research, 38(3), 303-328. doi:10.1007/BF00292050

Diener, E. (2006). Guidelines for national indicators of subjective well-being and Ill-Being. Journal of Happiness Studies, 7(4), 397-404.
Frisch, M.B. (2006). Quality of life therapy: A life satisfaction approach to positive psychology and cognitive therapy. Hoboken, NJ: John Wiley \& Sons

Neal, J.D., Uysal, M., \& Sirgy, M.J. (2007). The effect of tourism services on travelers' quality of life. Journal of Travel Research, 46(2), 154-163. doi:10.1177/0047287507303977

Felce, D., \& Perry, J. (1993). Quality of life: A contribution to its definition and measurement. Cardiff: University of Wales College of Medicine.

Pollard, E. L., \& Lee, P. D. (2003). Child well-being: A systematic review of the literature. Social Indicators Research, 61(1), 59-78. doi:10.1023/A:1021284215801

O’Donnell, G. (2014).Wellbeing and policy. London: Legatum Institute.

Møller, V., Huschka, D., \& Michalos, A. C. (2008). Barometers of quality of life around the globe: How are we doing? Dordrecht: Springer. 